\title{
Induction Motors Performance Study under Various Voltage Sags Using Simulation
}

\author{
Mansour Ojaghi *, Jawad Faiz **, Hamid Shahrouzi *, and Sahar Alimohammadi***
}

\begin{abstract}
The main aim of this paper is to study effects of different voltage sags and their intensity on the behavior of induction motors using a simulation approach. For this purpose, necessary simulation was done in Matlab - Simulink first. Then, to ensure-reasonable accuracy of the simulation, some results of the simulation were compared with the corresponding results measured in the laboratory. Then effects of intensity of symmetric voltage sag (three phase) and its starting point on the behavior of small and large induction motors was studied using simulation and subsequently, the effects of asymmetric voltage sags (single phase and two phase) has also been studied and finally the conclusion of the study was presented.
\end{abstract}

Keywords: Induction motors, Simulation, Voltage sag, Excessive current

\section{Introduction}

Much of the electrical energy conversion to mechanical energy is done by induction motors, which is why this type of electrical motor has been known as an industry work-horse. Power quality problems affecting induction motor behavior include voltage sags, harmonics, unbalance voltages, short interruptions, impulse surges, over voltage and under voltage. Reduced torque and speed (even a complete stall), increased losses, mechanical shock, insulation system damage, overheating and reduced life time are among consequences of such problems on the induction motor [1]-[3].

Meanwhile, the voltage sag is defined as voltage amplitude reduction from 10 to 90 percent at nominal frequency with durations from half cycle up to 1 minute. The major causes of voltage sags in electrical networks are:

- Start up of large induction motors.

- Start up of arc furnaces and other similar apparatus.

- Incidences of short circuit faults in the network.

- Load transfer from one source to another.

Some statistics on the voltage sags and their causes in the network are as follow [4]-[6]:

- Voltage sags are the main causes of disturbances within the network with an incidence between $61 \%$

\footnotetext{
* Dept. of Electrical Engineering, University of Zanjan, Iran. (mojaghi@znu.ac.ir) \& (h_shahrouzi@znu.ac.ir)

** School of Electrical and Computer Engineering, University of Tehran, Iran. (jfaiz@ut.ac.ir)

*** Department of Electrical Engineering, Zanjan Azad University, Iran. (sahar_alimohammadi@yahoo.com)

Received 29 February 2012; Accepted 01 August 2012
}

and $87 \%$ (depending on the source type).

- Most voltage sags have magnitude of around $80 \%$ and duration of four to ten cycles.

- Short circuit faults and subsequent voltage sags are $45 \%$ single-phase, $21 \%$ double-phase and $31 \%$ threephase.

Extreme loading on a working induction motor can also cause a voltage sag in the network [7]. So, while the induction motor is affected by voltage sags, in certain circumstances, it could be a cause of voltage sag in the network, too. The interaction between induction motor acceleration and voltage sag has been studied in [8]. But in [9] the effects of voltage sag on thermal and electrodynamics behavior of induction motors were investigated. To achieve this goal, the results obtained from practical experiments in some special cases of voltage sags were studied. Therefore, the presented results may not be regarded as general.

In this paper the simulation approach has been chosen to assess the effects of voltage sags on the performance of induction motor. Therefore, as there are no restrictions in simulating under different conditions, obtaining more complete and comprehensive results is possible.

For this purpose the simulations has been done by means of Simulink software and to ensure the accuracy and precision of simulation in presence of voltage sags, the simulation results are compared with the experimental results which are provided in [9]. Then, the effects of the degree of voltage sags and their start time on the motor performance are investigated. These investigations are performed separately for large and small induction motors 
which have different technical specifications. Also the effect of the various asymmetric voltage sags (single phase and two-phase) on motor behavior is studied. Comprehensive study done in this paper makes a good background for other studies in the field of thermal, electrodynamics and even mechanical effects of voltage sags on induction motors behavior.

\section{Essential Concepts}

In this section, some essential concepts used within the text are briefly introduced.

\subsection{Cold-Load Pickup}

This concept is briefly called CLP and is said to be an event through which an induction motor (or an electrical system) restarts after a relatively long period of stopping and losing all of its energy. Usually during CLP the line current drawn from the network is much greater than the nominal current. Another factor which affects the current amplitude during the CLP is the startup current, during which its amplitude reaches 5 to 8 times the normal current of the motor and lasts a few seconds.

\subsection{Loss of Load Diversity}

This concept is briefly called LLD. To have a better understanding of LLD, first its concept in the distribution system is explained. LLD takes place when energizing a system after a long time of separation from the network. Normally a distribution system contains a variety of consumers in such a way that at any time a number of consumers come on or off randomly and, of course, some consumers are permanently connected to the network. Experience has shown that during the occurrence of a CLP in the distribution system, its load becomes remarkably higher than its normal load. This is caused by synchronization of all consumers (even periodic consumers) demand. It usually lasts a few minutes and then, the system returns to its normal state. This temporary state is called LLD. The induction motor may also be faced with such a situation during CLP.

\subsection{Hot-Load Pickup}

This concept is briefly called HLP and is against the CLP. HLP is used to describe the motor (or the electrical system) recovery mode immediately after a fault occurrence and before a LLD could be happen. Usually during HLP, the motor still is not completely stopped and has some kinetic energy.

\subsection{Supplying Industrial Motors}

Industrial motors generally have a magnetic switch to connect them to mains, which needs enough voltage magnitude to stay attracted. In the case of power failure or excessive voltage sag, this switch may open and does not allow the motor to restart after removing the problem. Then it is necessary for the operation to restart the motor manually. Usually the delay in manual operation causes DLL and CLP.

\section{Induction Motor Performance Simulation under Voltage Sags}

The induction motor used for experiments was a small standard three-phase machine with the following ratings: $5.5 \mathrm{~kW}, 380 \mathrm{~V}, 50 \mathrm{~Hz}, 1450 \mathrm{rpm}$ and with load torque proportional to the squared speed [9]. Voltages and currents were measured and recorded through a 32 bits digital oscilloscope and a 32 bits standard power data analyzer. The investigated voltage sags were always balanced with durations of approximately five cycles. The load level was adopted equal to $85 \%$ of motor's rated load; a normal or typical load level for industrial motors. The event duration of about 5 cycles was selected based on the above mentioned occurrence probability [9]. Since accessing the detailed information of the above motor was not possible, a similar motor with the ratings of $5.4 \mathrm{hp}, 400 \mathrm{volts}, 50 \mathrm{~Hz}$, 1430rpm was selected for the simulation purpose. All the experiments done in [9] are simulated on this motor, too. The motor behavior analysis will be done by dividing the transients into two parts, namely on-event and post event phenomena. In the following, some experimental results from [9] along with obtained corresponding simulation results are presented.

\subsection{Open Circuit Terminals}

In the first test, while the motor works under no load, its stator terminals open from the mains for a period of about five cycles and then reconnect. In reality, such a situation may take place when the protection system trips the supply and then, recloses it, while there is no other circuit in parallel with the motor. Motor terminal voltages during open-circuited terminals are actually internal induced Electro-Motive Forces (EMFs). Fig.1 shows a terminal 
voltage waveform during this test obtained both by experiment and simulation. As seen, after open circuit occurrence, amplitude and frequency of EMF decline that is caused due to speed reduction. If the motor was under load, depending on the load level, motor speed reduction and the resultant reduce in the EMFs amplitude and frequency would be faster. Such changes of the internal EMFs can make it difficult to re-close the motor, because an out-ofphase occurs between EMSs and corresponding mains voltages. In the tested motor, a peak current of $160 \mathrm{~A}$ was seen after reclosing where the maximum starting current of the motor is 148A [9].

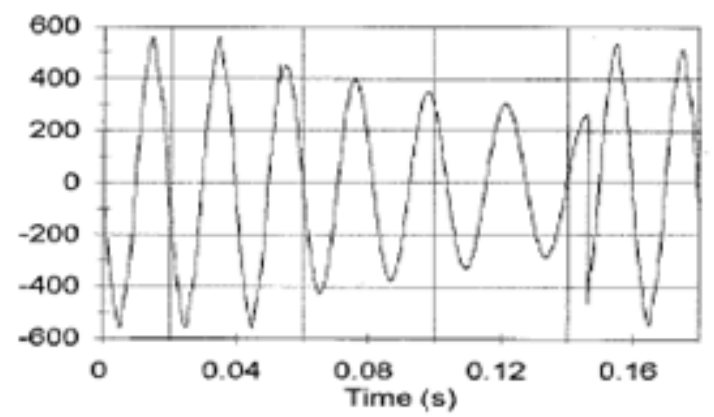

(a)

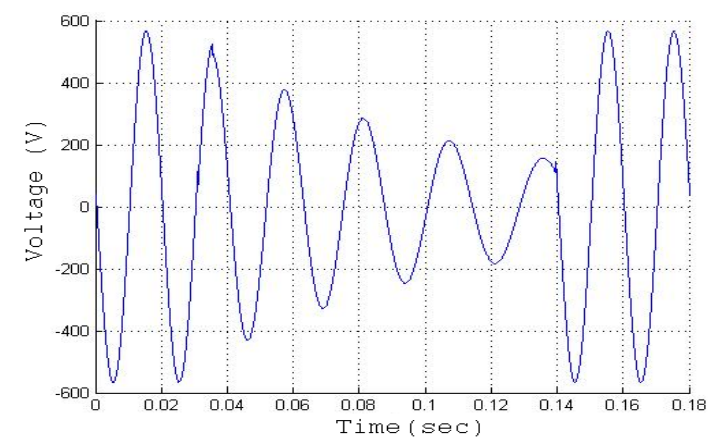

(b)

Fig. 1. Opening and reclosing of a no load motor and its EMF attenuation: a) Experimental, b) Simulation

As can be seen in Fig.1, simulation results are in good agreement with experimental results, although, damping phenomenon in the simulated motor was faster because of differing technical parameters of the two motors.

\subsection{Symmetrical Short Circuit}

In this test, during normal operation of the motor, a three phase short circuit occurred on the stator terminals for a period of 5 cycles. This is equal to voltage sag of $100 \%$. Line current waveforms during the fault and after the fault are shown in Fig.2. As seen, short circuit currents were attenuated very fast. Detailed analysis indicates that speed was reduced with a time constant of $0.1 \mathrm{~s}$. DC components of short circuit currents are also visible in Fig.2. The DC components decay is governed by the stator circuit timeconstant. Qualitatively, good agreement can be seen between simulation and experimental results, but like previous results, transient conditions in simulated motor were damped faster. In this condition, EMFs disappeared in less than 4 cycles. So, the re-connection of the normal three phase voltages to the stator terminals, after fault suppression, may be done normally [9].

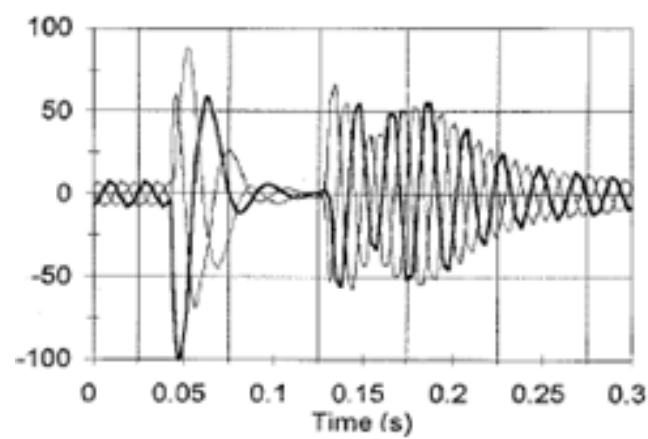

(a)

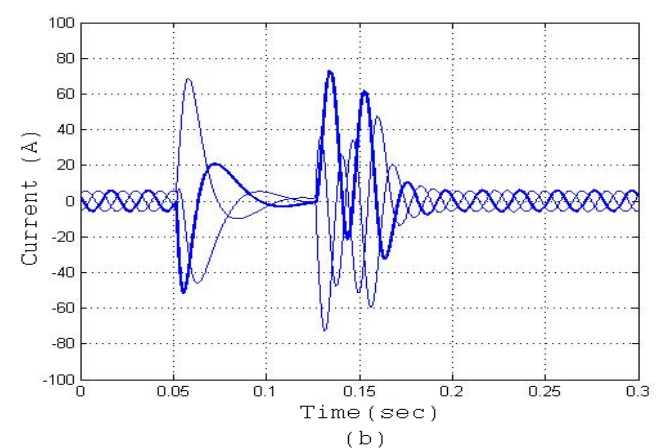

Fig. 2. Stator currents waveform during a three phase short circuit at its terminals (100\% voltage sag) under no load: a) Experimental, b) Simulation.

\subsection{Voltage Sag}

After considering the two extreme conditions of the open and short circuit previously, now we consider intermediate conditions, where voltage sag exists but its amplitude is much less than $100 \%$. A three phase short circuit in a point far away from the motor's terminals can be a cause of this voltage sag. In this case, the final value of the voltage sag depends on distance of the fault location from the motor as well as the motor load level. In this subsection, experimental and simulation results due to two cases of symmetrical voltage sags, one with a $70 \%$ decrease (deep voltage sag) and the other with a $15 \%$ decrease (shallow voltage sag) of voltage amplitude, are considered.

Fig. 3 shows a stator line current after the occurrence of $70 \%$ symmetrical voltage sag with a 5 cycle's duration. As 
seen, the current was increased at first, and then, after the end of magnetic transience, its amplitude was decreased gradually. If duration of voltage sag increases, the current amplitude will begin to increase again due to reduced EMFs, which is because of motor speed reduction, but with a 5 cycle duration, the maximum-current occurred at the start point and its amplitude was three times the motor nominal current. This value is two times the nominal current at the end of the voltage sag. Nevertheless, during this voltage sag, calculation shows that wasted energy in motor conductors (i2dt) is five times the state in which the motor works at $85 \%$ of its rated load. A good agreement can be seen between experimental and simulation results. Again transient attenuation in the simulated motor is faster.

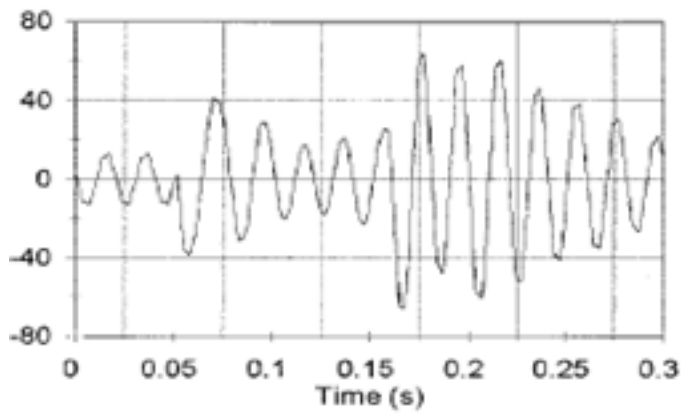

(a)

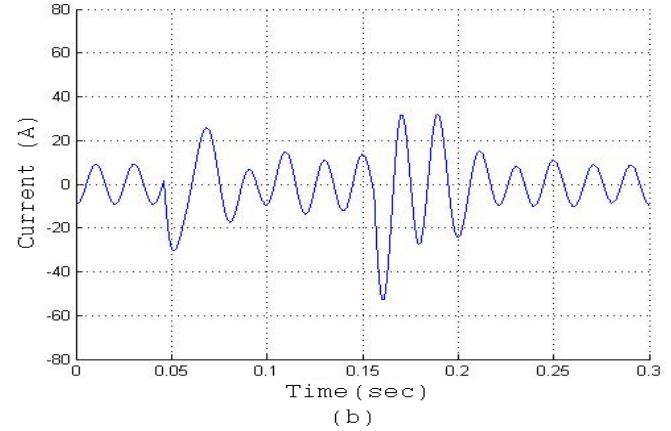

Fig. 3. Motor current waveform during a $70 \%$ voltage sag under 85\% nominal load: a) Experimental, b) Simulation.

A stator line current waveform after an occurrence of $15 \%$ symmetrical voltage sag with a 5 cycle duration was shown in Fig.4. Motor current in this condition is approximately $20 \%$ higher than its nominal current and speed reduction isn't sensible. In this condition, wasted energy in motor conductors doesn't show much difference $f$ rom that of motor's normal operation under $85 \%$ rated load. A good agreement can be seen between experimental and simulation results. Little difference in current magnitude between the simulation and experimental results is due to the difference between the motors' ratings.

As indicated in this section, there is an acceptable agreement between the experimental and corresponding simulation results. This verifies the accuracy and precision of the simulation program and process. Using this simulation tool, more comprehensive studies regarding the effects of voltage sag on the behavior of the induction motors will be provided in the following sections.

\section{Induction Motor Performance Due to Magnitude and Start Point of Symmetrical Voltage Sags}

One of the main factors which reduce electrical machines' life times is excessive current flow through their windings.

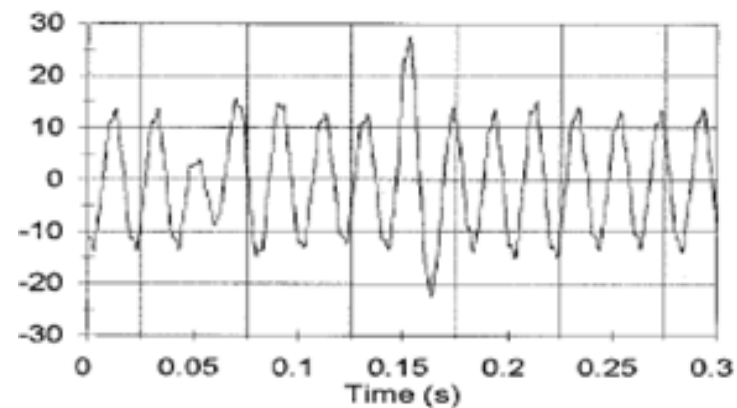

(a)

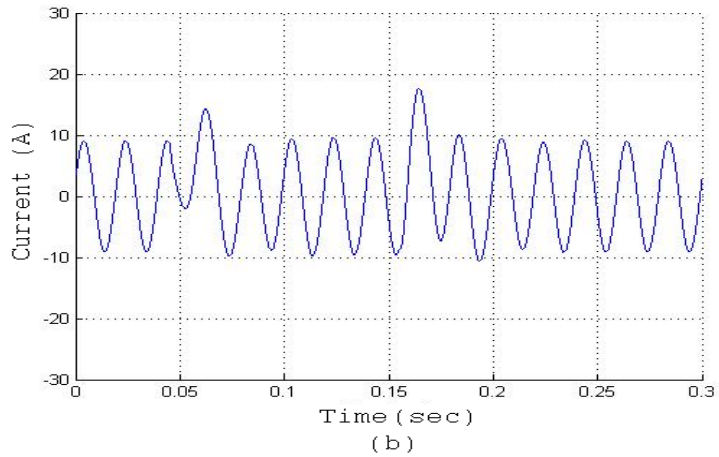

Fig. 4. Motor current waveform during a $15 \%$ voltage sag under 85\% nominal load: a) Experimental, b) Simulation

Excessive current reduces their life expectancy and causes premature aging in machines through increasing thermal stresses and electromagnetic effects on insulation. The severity of adverse effects of excessive current on the machine is a function of current amplitude and its duration. So, high currents occurring over very short time periods may also be problematic. In the previous section, it was noted that according to deepness of the voltage sag, the induction motor's winding current may be increased impressively in starting, duration and end of the voltage sags. In this section, the effects of symmetrical voltage sag magnitude as well as its starting point (with regard to the sinusoidal voltage waveform) on the maximum pick current of the windings and some other effects are investigated in detail. For this purpose, the simulation method, whose precision and accuracy was confirmed in the previous 
section, is used. Numerous simulations were carried out on the $5.4 \mathrm{hp}$ induction motor, where various three-phase voltage sags with variable degrees from 0 to $100 \%, 5$ cycles of duration and starting points coinciding at the zero crossing point of phase ' $A$ ' voltage waveform were applied to it, while it was operating under $85 \%$ of its nominal load. Also, similar simulations were carried out with starting points coinciding with positive peak points of phase ' $A$ ' voltage waveforms. Under these conditions, the maximum

pick current of stator windings was read after the start and after end of the voltage sags. The results are presented in Fig. 5. As there are some differences between transient operations of large induction motors compared to small ones [10], all mentioned simulations were performed on a $215 \mathrm{hp}$ induction motor. Technical specifications of this motor are presented in [10]. The results achieved for this motor are presented in Fig. 6. According to Figs. 5 and Fig. 6 , the following consequences are accessible:

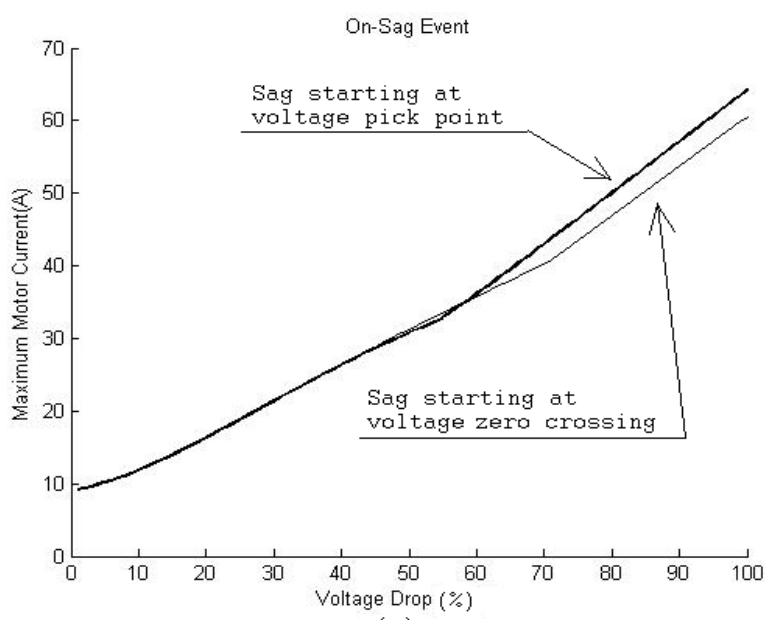

(a)

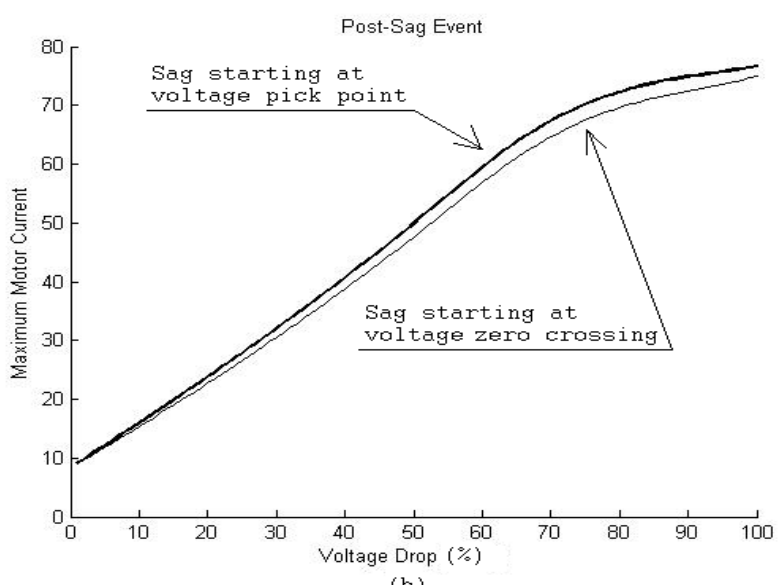

(b)

Fig. 5. 5.4 hp motor maximum peak current v.s. voltage sag degree for sag starting near voltage peak point and near its zero crossing point: a) on-sag event, b) post-sag event
- In small motors, the occurrence of excessive currents with great amplitude is more probable when the start time of the voltage sag is close to the peak of the voltage

waveform, while in large motors the current amplitude becomes greater when the voltage sag start time is close to the zero crossing of the voltage waveform.

- In large motors, on event current peak amplitude after sag start is almost a linear function of the voltage sag degree. This linear relationship is almost true for post event current peak amplitudes up to a voltage sag degree of $70 \%$.

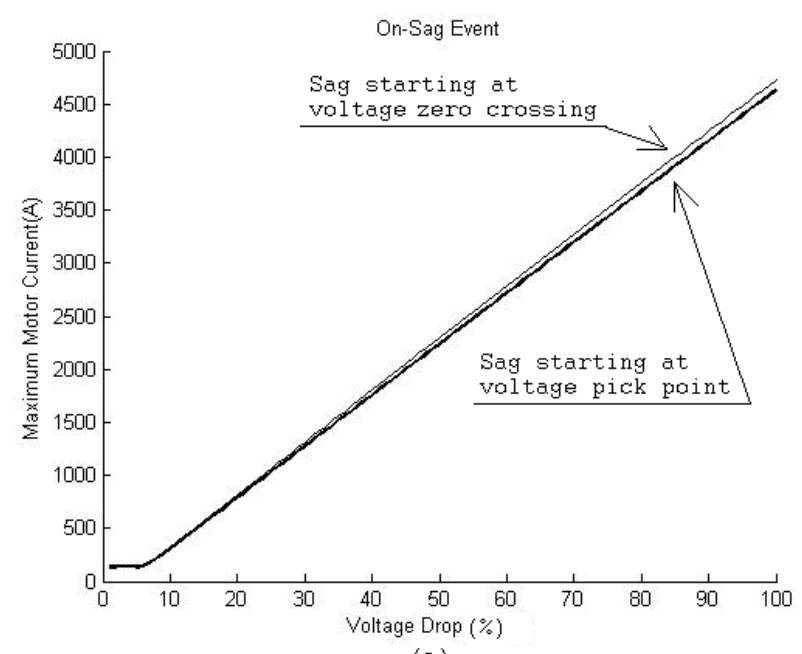

(a)

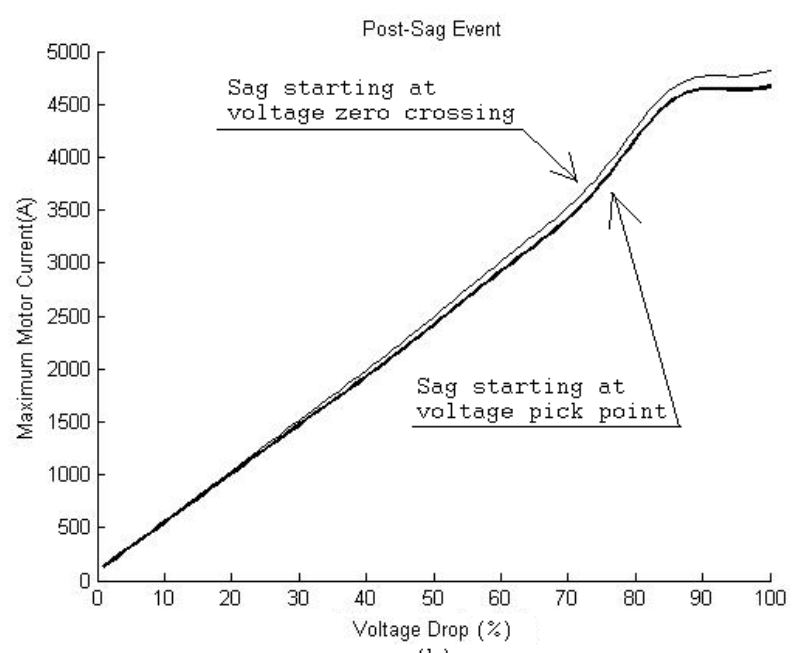

(b)

Fig. 6. $215 \mathrm{hp}$ motor maximum peak current v.s. voltage sag degree for sag starting near voltage peak point and near its zero crossing point: a) on-sag event, b) post-sag event

- In large motors, when the voltage drop is less than 5\%, Event current peak amplitude almost remains constant. 
Also in these motors when the voltage drop is more than $90 \%$, the post event current peak amplitude remains constant.

\section{The Impact of Asymmetrical Voltage Sags}

When only one or two phase voltages are affected, the relevant voltage sags are called asymmetrical. In this section, the asymmetrical voltage sags effects on induction motors behavior are studied. As single phase to ground and double phase short circuits are the main causes of asymmetrical voltage sags, these kinds of faults are used to simulate the asymmetrical voltage sags. The simulations were done on the $5.4 \mathrm{hp}$ induction motor. First, when there was no load operation of the motor, a relevant short circuit was applied to its terminals for about 5 cycles. Fig. 7 shows the

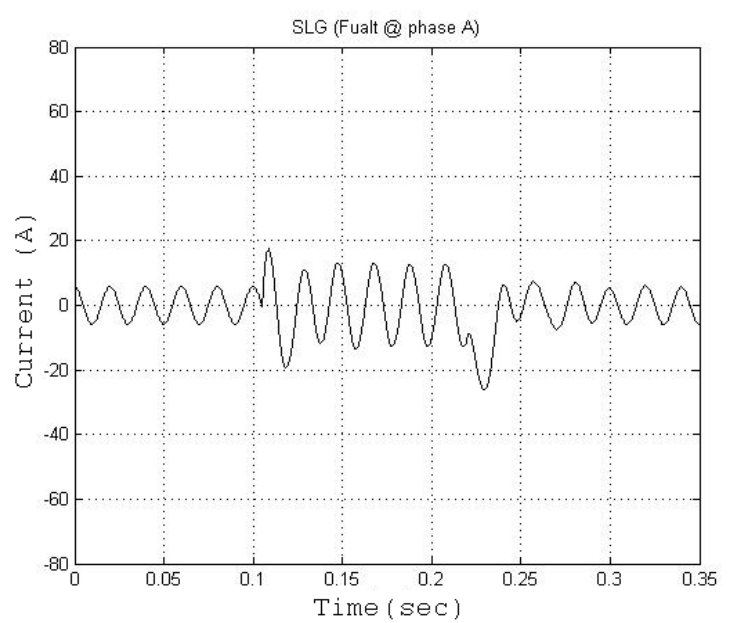

(a)

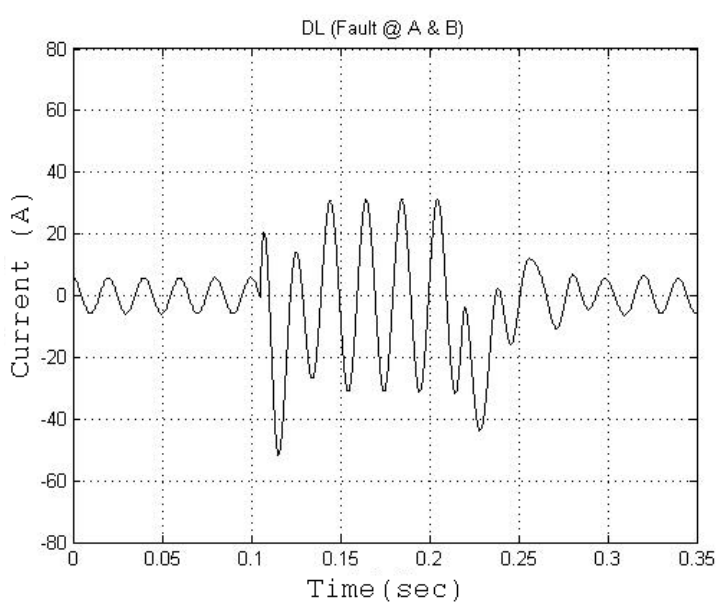

(b)

Fig.7. Motor current waveform during asymmetric voltage sags under no load: a) single phase, b) double phase

motor line current waveform in a faulty phase. As seen, both voltage sag types have increased the amplitude of the current waveform after the start and also after the end of the sags. In addition, it can be seen that the amplitude of the current waveform due to double phase sag has a higher value. Similar simulations were done in which the motor was under $85 \%$ of its rated load, but small increases in current amplitudes was observed.

\section{Discussion}

The ratio of maximum motor current due to voltage sag to the motor rated current was examined at no load and at $85 \%$ of rated load conditions for all voltage sag types. The results are presented in Table I. Comparison of the values listed in this table indicates that symmetrical voltage sag may create the most acute problem for the motor and after that, double phase voltage sag with a little difference is the second most acute problem, and finally, single phase voltage sag with the lowest ratio is the most low-risk voltage sag for the motor.

\section{Conclusion}

Behavior of induction motors due to voltage sags can be studied using simulation. This way, good agreement with experimental results could be achieved. Depending on the amount and type of voltage sag, reacceleration of the motor would be difficult and consequently high current drawn from a source would cause thermal stresses in the motor. Behavior of induction motors with different sizes would be different in facing voltage sags with different start times. Large motors' behavior in facing voltage sag is different from small motors and this should be taken into consideration during operation. The most dangerous type of voltage sag for induction motors is symmetrical three phases, and the single phase voltage sag is the most low-risk one.

Table 1. Wasted energy in stator windings during excessive current due to votage sags

\begin{tabular}{cccc}
\hline Voltage sag type & $\begin{array}{c}\text { Single } \\
\text { phase }\end{array}$ & $\begin{array}{c}\text { Double } \\
\text { phase }\end{array}$ & Three phase \\
\hline $\begin{array}{c}\text { Max Motor } \\
\text { Current/Nominal Current } \\
(\text { No- } \text { load) }\end{array}$ & 4.72 & 11.26 & 14.11 \\
\hline $\begin{array}{c}\text { Max Motor } \\
\text { Current/Nominal Current } \\
(\text { 85\% rated load) }\end{array}$ & 4.72 & 12.43 & 14.11 \\
\hline
\end{tabular}


Table 2. Wasted energy in stator windings during excessive current due to votage sags

\begin{tabular}{cccc}
\hline Voltage sag type & Single phase & $\begin{array}{c}\text { Double } \\
\text { phase }\end{array}$ & Three phase \\
\hline$W_{\text {loss }}(J)$ & 29.62 & 111.11 & 137.5 \\
\hline
\end{tabular}

\section{References}

[1] G. T. Heydt, Electric Power Quality, Scottsdale, AZ: Starts in a Circle, 1991.

[2] C. Sankaran, Power Quality, CRS PRESS, Washington, D.C., 2007.

[3] Lan K.p.Ross, Omniverter Inc, “ Voltage Sags: an Explanation, Cause, Effects and Correction-Part1," November 2007.

[4] D. S. Dorr, M. B. Hughes, T. M. Gruzs, R. E. Jurewicz, and J. L. Mc-Claine, "Interpreting Recent Power Quality Surveys to Define the Electrical Environment," vol. 33, pp. 1480-1487, Nov./Dec. 1997.

[5] E. W. Gunther and H. Mehta, "A Survey of Distribution System Power Quality - Preliminary Results, ”, vol. 10, pp. 322-329, Jan. 1995.

[6] L. Tang, J. Lamoree, M. McGranagham, and H. Mehta, "Distribution System Voltage Sags: Interaction with Motor and Drive Loads," in Chicago, IL, 1994

[7] G. S. Grewal, "Transient Motor Reacceleration Study in an Integrated Petrochemical Facility," IEEE Trans. Industry Applicat., vol. 35, pp. 968-977, July/Aug. 1999.

[8] M. H. J. Bollen, "The Influence of Motor Reacceleration on Voltage Sags,” vol. 31, pp. 667-674, July/Aug. 1995.

[9] J. C. Gomez, "Behavior of Induction Motor Due to Voltage Sags and Short Interruptions," vol. 17, no. 2, pp.434-440, April 2002.

[10] P. C. Krause, Analysis of Electric Machinary, McGraw Hill,1991.

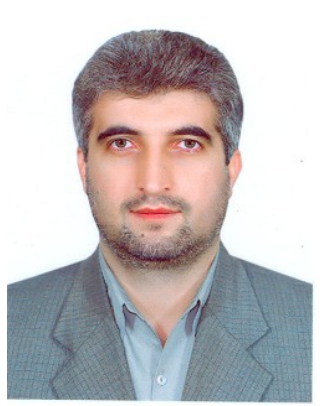

Mansour Ojaghi received his B.Sc. degree from Shahid Chamran University, Ahwaz, Iran in 1993, M.Sc. degree from the University of Tabriz, Tabriz, Iran in 1997, and Ph.D. degree from the University of Tehran, Tehran, Iran, in 2009 all in electrical engineering. He was with the Zanjan Regional Electricity Company for 10 years, where he held the position of Manager of Grid Technical Office. He is currently with the University of Zanjan, Zanjan, Iran, as an Assistant Professor. Dr. Ojaghi is a Member of Power and Energy, Industry Applications, Industrial Electronics, Magnetics and Education Societies of the IEEE. His research interests include modeling, simulation, and fault diagnosis of electrical machines and drives, as well as power-system protection.

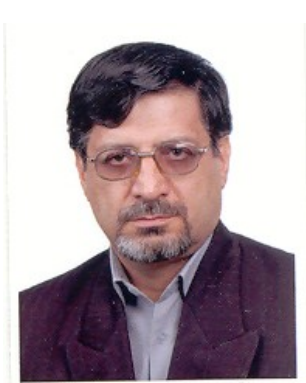

Jawad Faiz received the Master's degrees in electrical engineering from the University of Tabriz in Iran in 1975 graduating with First Class Honors. He received the Ph.D. degree in Electrical Engineering from the University of Newcastle upon Tyne, England in 1988. Early in his career, he served as a faculty member in the University of Tabriz for 10 years.

After obtaining Ph.D. degree he rejoined the University of Tabriz where he held the position of Assistant Professor from 1988 to 1992, Associate Professor from 1992 to 1997, and has been a professor since 1998. Since February 1999 he has been working as a professor at the School of Electrical and Computer Engineering, Faculty of Engineering, University of Tehran. He is currently the director of the Center of Excellence on Applied Electromagnetic systems. He has received a number of awards including the first basic research award from the Kharazmi International Festival in 2007, the silver Einstein medal for academic research from the UNESCO, the first rank medal in Research from the University of Tehran in 2006, the Elite Professor Award from the Iran Ministry of Science, Research and Technology in 2004.

$\mathrm{He}$ is the author more than 170 papers in international journals and 172 papers in international conference Proceedings. Dr. Faiz is a Senior Member of Power Engineering, Industry Applications, Power Electronics, Industrial Electronics, Education and Magnetics Societies of the IEEE. He is also a member of Iran Academy of Science. His teaching and research interests are switched reluctance and VR motor design, design and modeling of electrical machines and drives, transformer modeling and design and fault diagnosis in electrical machinery.

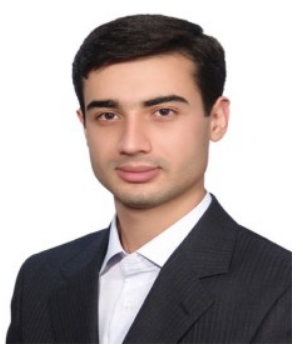

Hamid Shahrouzi received his B.Sc. and M.Sc. degrees in electrical power engineering from the University of Zanjan, Iran in 2008 and 2011 respectively.

His research interests include Transformer Modeling, Artificial Optimization Algorithms and simulation of electrical machines. 
Sahar Alimohammadi received her B.Sc. in electronic engineering from the University of Zanjan, Iran in 2008 and M.Sc. in electrical power engineering the University of Tafresh, Iran in 2010 respectively.

Her research interests include generation expansion planning and simulation of electrical machines. 